\title{
SEVERE CRYPTOGENIC MULTIFOCAL ULCEROUS STENOSING ENTERITIS. A REPORT OF THREE CASES AND REVIEW OF THE LITERATURE
}

\author{
Darina Kohoutová ${ }^{1}$, Jan Bureš ${ }^{1}$, Věra Tyčová2 ${ }^{2}$ Jolana Bártová1, Ilja Tachecí1, Stanislav Rejchrt ${ }^{1}$, Zdeněk Vacek ${ }^{3}$, \\ Rudolf Repák ${ }^{1}$, Marcela Kopáčová ${ }^{1}$
}

Charles University in Prague, Faculty of Medicine and University Hospital Hradec Králové, Czech Republic: $2^{\text {nd }}$ Department of Internal Medicine, Division of Gastroenterology ${ }^{1}$, The Fingerland Department of Pathology ${ }^{2}$, Department of Radiology ${ }^{3}$

\begin{abstract}
Summary: Cryptogenic multifocal ulcerous stenosing enteritis (CMUSE) is a rare condition characterised by chronic or relapsing moderate ileous episodes resulting from multiple small intestinal strictures, multiple shallow ulcers of the small bowel and favourable therapeutical effect of glucocorticosteroids. The aim of this paper was to evaluate three cases of CMUSE diagnosed within 10 years at a tertiary gastroenterology centre. Three females $(35,50,60$ years $)$ were presented with colicky pain, repeated moderate ileous episodes and weight loss. Multiple fibrous strictures and ulcers of the small bowel were found. All three patients responded to glucocorticosteroid treatment. Tandem tight jejunal stenoses were dilated endoscopically by means of double balloon enteroscopy. In conclusion, CMUSE should always be considered when chronic moderate ileous episodes and multiple small intestinal strictures and ulcers of uncertain aetiology are found. Double balloon enteroscopy enables precise diagnostic work, possible endoscopic treatment of stenoses, may obviate the need for surgery and prevent excessive small bowel resections.
\end{abstract}

Key words: Cryptogenic multifocal ulcerous stenosing enteritis; Moderate ileous episodes; Small intestinal ulcers; Glucocorticosteroids

\section{Introduction}

Cryptogenic multifocal ulcerous stenosing enteritis (CMUSE) is a rare condition characterised by chronic or relapsing moderate ileous episodes resulting from multiple small intestinal strictures, multiple shallow ulcers of the small bowel and beneficial therapeutical effect of glucocorticosteroids $(1,2)$. Japanese gastroenterologists call this syndrome chronic non-specific multiple ulcers of the small intestine (CNSU) (3). The aetiology of CMUSE has not been clarified yet and pathogenesis is still poorly understood. Some authors even doubt the real existence of this entity.

Patients with CMUSE are often referred for surgery because of symptomatic small intestinal strictures and several resections of the small bowel had to be performed.

We report three cases of CMUSE diagnosed within the past 10 years at a single tertiary centre, where more than eight thousand GI endoscopies are performed per year. Review of available relevant literature is provided.

\section{Case reports}

\section{Case 1}

A 35-year-old woman was admitted to our department because of chronic diarrhoea, colicky abdominal pain, weight loss (16 kg during previous five years) and repeated moderate ileous episodes. She was cachectic (body-mass index $12.8 \mathrm{~kg} / \mathrm{m}^{2}$ ). Laboratory tests showed iron-deficiency anaemia (haemoglobin $96 \mathrm{~g} / \mathrm{L})$, thrombocytosis $\left(459.10^{9} \mathrm{~g} / \mathrm{L}\right)$ and proteino-energy malnutrition (serum prealbumin 0.17 $\mathrm{g} / \mathrm{L}$ ). Abdominal ultrasound revealed strenuous small intestinal peristalsis and a large volume of fluid in the intestinal loops. Enteroclysis provided no further information. Gastroscopy and colonoscopy were normal. Push-enteroscopy found multiple shallow ulcers of the distal duodenum and proximal jejunum (Fig. 1) and increased stagnant fluid content in the proximal part of the small bowel. A non-specific inflammatory process was detected at histology and electron microscopy of small intestinal biopsy specimens. Coeliac disease, lymphoma, Crohn's disease and vasculitis were excluded. No infective agent was found. Total parenteral nutrition and glucocorticosteroids improved her general condition including nutritional status (serum albumin $35.8 \mathrm{~g} / \mathrm{L}$, prealbumin $0.29 \mathrm{~g} / \mathrm{L}$, body-mass index $13.4 \mathrm{~kg} / \mathrm{m}^{2}$ ). The patient was discharged on enteral nutrition, glucocorticosteroids (prednisone was gradually replaced by budesonide) and 5-aminosalicylates. She was followed-up at regular controls. Nine months later the patient had to be admitted because of a worsened general condition (frequent watery stools, fatigue, oedemas of lower extremities, fluidothorax and ascites). Laboratory tests revealed hypo- 
kalaemia $(2.2 \mathrm{mmol} / \mathrm{L})$, hypomagnesaemia $(0.51 \mathrm{mmol} / \mathrm{L})$, low serum albumin $(15.7 \mathrm{~g} / \mathrm{L})$ and prealbumin $(0.10 \mathrm{~g} / \mathrm{L})$, elevated liver enzymes and high C-reactive protein (136 $\mathrm{mg} / \mathrm{L}$ ). Capsule endoscopy was performed and multiple ulcers of the duodenum, jejunum and ileum were found. Despite no evident stenosis at repeated preceding enteroclysis, asyptomatic capsule retention in the distal ileum occurred. Her general condition improved by means of systemic glucocorticosteroids and total parenteral \& enteral nutrition within two months again. Nevertheless she was not fit for surgery. The patient died after further 7 months as a result of fulminant bilateral bronchopneumonia complicated by sepsis. Six

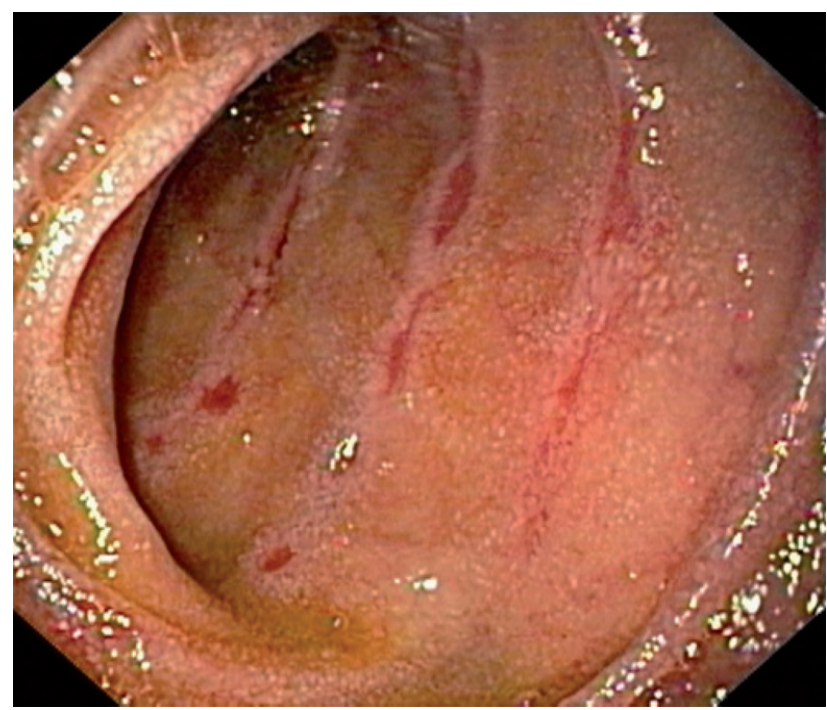

Fig. 1: Push-enteroscopy. Multiple shallow ulcers were found on the top of transverse folds in the proximal jejunum.

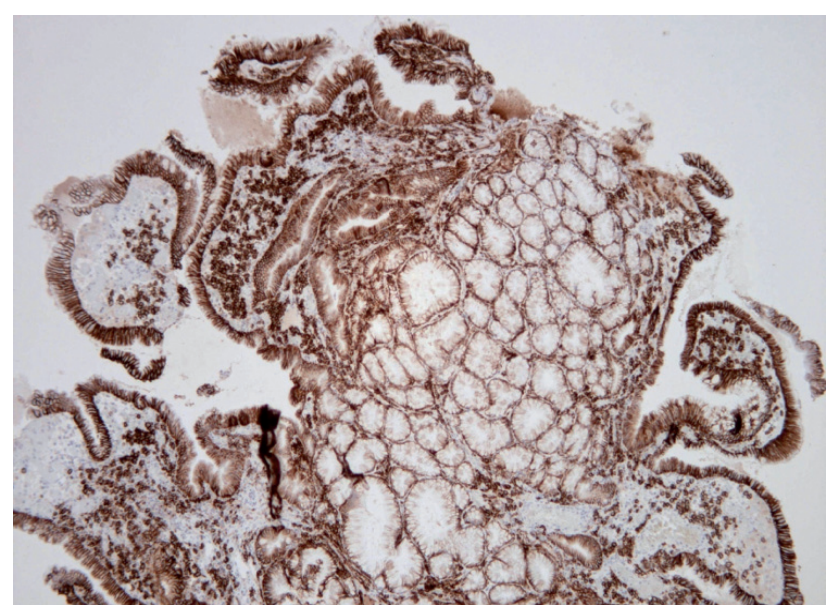

Fig. 3: Prevailing infiltration with plasmatic cells was identified in all layers of the small intestine. Immunohistochemistry, anti-CD138 staining, magnification 100x. short stenosing fibrous strictures of the small intestine and disintegrated video capsule were found at autopsy.

\section{Case 2}

A 60-year-old woman was referred to our department because of severe malnutrition, weight loss $(10 \mathrm{~kg}$ per month), diarrhoea, low-grade fever, fatigue and breathlessness. Bilateral fluidothorax, pericardial effusion, ascites and severe oedemas of low extremities were found on admission. Iron-deficiency anaemia $(94 \mathrm{~g} / \mathrm{L})$, leukocytosis $\left(24.10^{9} / \mathrm{L}\right)$ and thrombocytosis $\left(426.10^{9} / \mathrm{L}\right)$ were found. Biochemical tests showed low serum albumin (15.2 g/L),

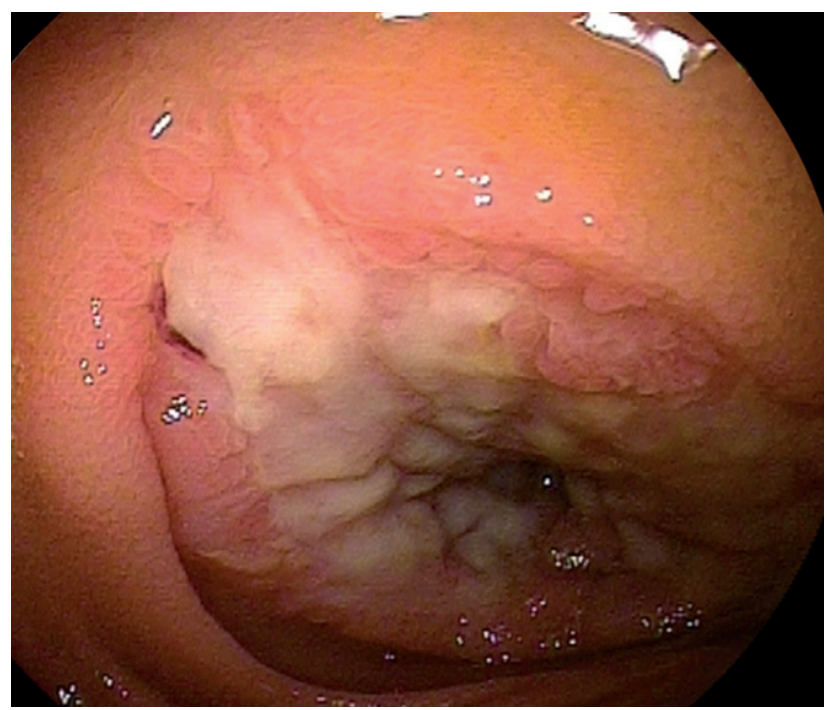

Fig. 2: Double balloon enteroscopy. A large but shallow ulcer is seen in front of tight fibrous stricture of the distal jejunum.

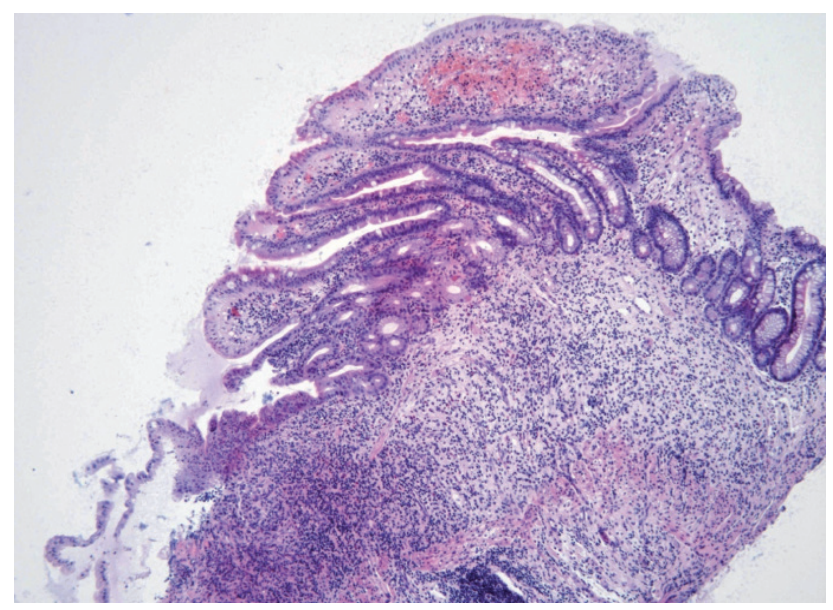

Fig. 4: Increased content of collagen was found in interstitial tissue of the small bowel. Small intestinal epithelium, impaired by extensive infiltration with plasmatic cells and lymphocytes. Optical histology, haematoxilin-eosin staining, magnification 40x. 
prealbumin $(0.06 \mathrm{~g} / \mathrm{L})$ and high C-reactive protein $(165$ $\mathrm{mg} / \mathrm{L})$. Gastroscopy revealed multiple ulcers of the duodenum, shallow ulcers were also found in the caecum and ascending colon at colonoscopy. Capsule endoscopy identified segmental ulcerative involvement of the small intestine (different from that seen in Crohn's disease). Double balloon enteroscopy showed multiple shallow ulcers of the duodenum and jejunum and multiple jejunal stenoses (Fig. 2). Non-specific inflammation of biopsy specimens was found at histology, consisting of neutrophils, eosinophils and both $\mathrm{B}$ and $\mathrm{T}$ lymphocytes. There was a marked infiltration of all layers by plasmatic cells (Fig. 3) and overproduction of collagen was recognised (Fig. 4). Flow cytometry of a small intestinal biopsy specimen revealed $\mathrm{CD}^{+}{ }^{+} \mathrm{CD} 8^{+} \mathrm{T}$ cells, no subset of $\mathrm{CD} 3^{+} \mathrm{CD} 8^{-} \mathrm{T}$ lymphocytes was identified. Infective aetiology, vasculitis and malignancy were excluded. Complex therapy including total parenteral \& enteral nutrition and systemic glucocorticosteroids improved her general condition and laboratory parameters (albumin $34.4 \mathrm{~g} / \mathrm{L}$ ). During the subsequent 3 months the patient remained symptom free despite persisting multiple small intestinal stenoses at control enteroclysis (Fig. 5). Control double balloon enteroscopy confirmed healing ulcers and three tight jejunal stenoses were dilated endoscopically up to $18 \mathrm{~mm}$ in diameter. Replacement of prednisone by budesonide was unsuccessful, acute moderate ileous episode occurred and forced a return to prednisone. Switching of systemic glucocorticosteroids to methotrexate was tried (parallel treatment was administered for 8 weeks). However, the moderate ileous status occurred again three weeks after withdrawal of the prednisone. At this moment, corticodependence of the disease has been definitely confirmed and a prednisone dose of $20 \mathrm{mg}$ daily is used as the basic treatment.

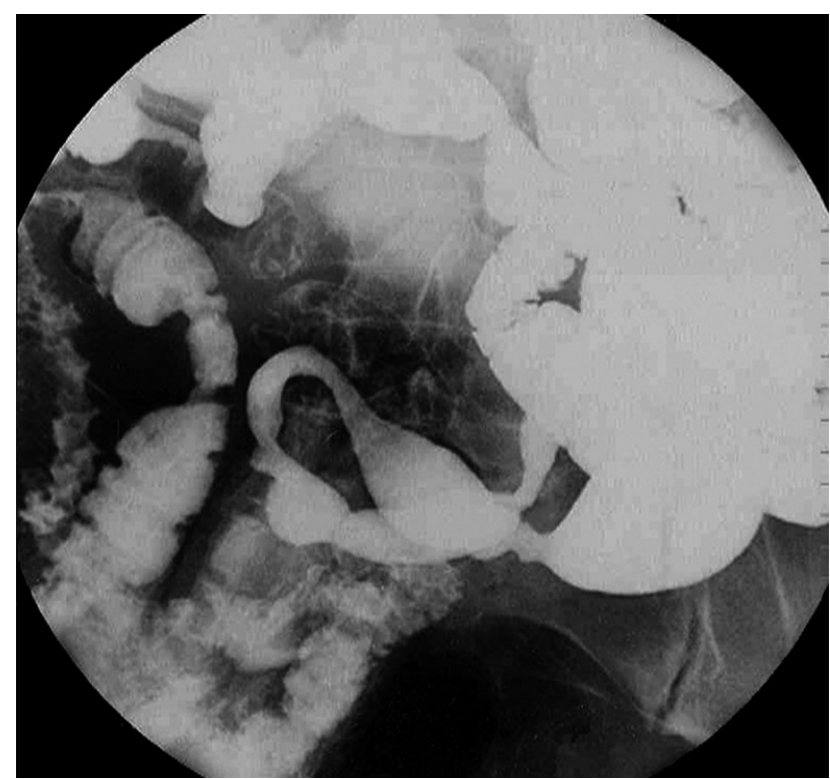

Fig. 5: Enteroclysis. Multiple persisting stenoses of the small intestine caused by fibrous strictures.
Case 3

A 50-year-old woman suffered for five years from colicky abdominal pain, recurrent moderate ileous episodes and collapses during difficult defecation. Repeated colonoscopies, enteroclyses and laparoscopy were performed elsewhere without any diagnostic progress. She was referred to our department at this point. Body mass index was 19.7 $\mathrm{kg} / \mathrm{m}^{2}$, laboratory findings (including nutritional parameters) were normal. Capsule enteroscopy detected erosions and small ulcerations in the ileum. Double balloon enteroscopy followed, multiple shallow ulcers were seen in the terminal ileum. Non-specific inflammatory histology was found with neutrophils, eosinophils, plasmatic cells and increased content of collagen. Gastrointestinal infection, Crohn's disease, vasculitis and malignancy were excluded. Budesonide ( $9 \mathrm{mg}$ per day) was sufficient to achieve full remission. The patient remained symptom free during 9 months of subsequent follow-up.

None of these three patients took any non-steroidal antiinflammatory drugs.

\section{Discussion}

We present three cases of CMUSE collected within the past 10 years at our department. The first descriptions of this rare condition probably came from the late 50's and early 60 's $(4,10,12,22,32,41)$, followed by further case reports or small series $(2,3,7,18,46,48)$. Matsumoto et al. (33) informed that Okabe and Sakimura reported first cases of CMUSE in Japan in 1968. However, all these early reports are difficult to evaluate nowadays as diagnostic potential was limited at that time. Nowadays, owing to double balloon enteroscopy we are able to investigate the entire small intestine $(9,29)$, take numerous biopsy specimens and utilise other advanced diagnostic methods like flow cytometry and/or immunohistochemistry. That is why several distinct entities can be newly recognised.

Only about fifty cases of CMUSE have been published so far $(9,33,34,37,46,42)$ but this entity has probably been considerably underdiagnosed or misdiagnosed, mostly with Crohn's disease and non-steroidal anti-inflammatory drugs (NSAIDs) induced enteropathy. Perlemuter et al. (37) reported 12 cases of CMUSE hospitalised between 1965 and 1993. This was a retrospective analysis of medical records based on queries sent to 220 French gastroenterology departments. Despite surgery, symptoms re-occurred in seven of ten patients and recurrence of strictures was reported in four. Inflammatory infiltrate was made of neutrophils and eosinophils. Steroid therapy was effective but caused dependence (37). Chang et al. (9) collected 2 cases of CMUSE diagnosed by means of double balloon enteroscopy in 48 patients (a series from 6 university hospitals in Korea). Both individuals suffered from chronic recurrent abdominal pain. One patient was presented with recurrent melaena (for 41 months), the other one was referred for surgery because of retention of a capsule endoscope in the ste- 
notic site. There were multiple small intestinal stenoses, shallow ulcers and mixed inflammatory infiltrate at histology (plasma cells, monocytes, neutrophils and eosinophils). Mesenteric arteriography did not demonstrate any evidence of arteritis (9).

Immunopathological pathogenesis of CMUSE is supported by the favourable therapeutical effect of glucocorticosteroids. Most of these patients become corticodependent (37, 44). All our three patients positively responded to this treatment and indeed 2 of 3 became dependent on glucocorticosteroids. The key to the solution of aetiology and understanding pathogenesis might be overstimulated production of fibrous tissue. This is a principal sign of CMUSE, responsible for chronic or relapsing moderate ileous episodes. Fibroblast proliferation can be augmented by pro-inflammatory cytokines (IL-6, IL-8, TNF-alpha), fibroblast growth factors (FGS II), granulocyte/macrophage colony-stimulating factor (GM-CSF), transforming growth factor beta (TGF-beta), platelet-derived growth factor (PDGF) (47) but also by endotoxin (lipopolysaccharide) (49). Other growth factors, such as the connective tissue growth factor (CTGF), which is secreted by fibroblasts and endothelial cells, also promote formation of fibrous tissue (47). Collagen is degraded by a family of matrix metalloproteinases that includes the collagenases. Matrix cells, neutrophils, and macrophages all secrete these proteinases. In healthy people, the degradation of collagen can be very rapid, and begins immediately after collagen is produced (1). We can hypothesise that multifocal small intestinal disturbance of collagen degradation in CMUSE might play a crucial role in pathogenesis. In CMUSE, fibrous tissue formation can be associated with low or even absent systemic inflammatory response (37).

We do not agree with Perlemuter et al. $(37,38)$ that CMUSE could be termed as a type of "atypical vasculitis". Any type of vasculitis of any cause, if found, should be assigned simply as "vasculitis" not CMUSE. Small intestinal involvement can be found in Churg-Strauss syndrome (20, 27, 36), systemic lupus erythematosus (43), Buerger's disease (30), Wegener's granulomatosis (11), Weber-Christian disease (28) and systemic sclerosis (13). Vasculitis could be associated with multiple small intestinal ulcers and their complications (including perforation) but quite rarely with multifocal stenoses of the small bowel. Furthermore, vasculitis mostly represents a systemic involvement (kidneys, skin, joints, lungs etc.). None of our three patients revealed any extra-intestinal involvement and small intestinal histology found no signs of vasculitis. Matsumoto (33) did not reveal any arteritis in his series as well. Perlemuter et al. (38) suggested the association of CMUSE with C2 complement deficiency; however, this was not confirmed by other authors (44). Recently, Fraile et al. (16) reported an association of CMUSE with X-linked recessive reticulate pigmentary disorder. Hussey et al. (23) published a case of CMUSE as a manifestation of enterocolic venopathy.

Chronic or relapsing moderate ileous episodes resulting from multiple small intestinal strictures are a leading clinical symptom $(33,37)$. All our three patients suffered from such episodes. Wireless capsule endoscopy was complicated by retention of the capsule in one of our cases of CMUSE. Spontaneous disintegration of a retained video capsule was reported by our group recently (45). Multiple small intestinal fibrous strictures were previously resected surgically (44), nowadays they can be treated endoscopically by means of double balloon enteroscopy (39). Three tight tandem stenoses of one of our patients with CMUSE were solved by balloon dilatation within double balloon enteroscopy.

In differential diagnosis of CMUSE, first of all Crohn's disease $(9,15)$, NSAIDs-induced enteropathy $(9,35)$, tuberculosis and other infections of the small bowel $(8,9,20)$, Behcet disease $(19,21,24)$ and malignancies must be excluded. It is a well-known fact, that the majority of extranodal malignant lymphoma involves the gastrointestinal tract. Not only polypoid and diffuse types of this disease, but also the ulcerative one can be detected in the small bowel (50). Usually either diffuse large B cell lymphoma or mucosa-associated lymphoid tissue (MALT) lymphoma are confirmed by histological methods (31).

It is also obligatory to distinguish CMUSE from other non-frequent pathological conditions. We are convinced that CMUSE is distinct from chronic ulcerative jejunitis $(14,25)$, collagen sprue (17) and from autoimmune or eosinophilic enteritis $(9,40)$. Similarly, non-specific small intestinal ulcers $(5,6,9,26)$ should not be considered to be CMUSE if multiple stenoses of the small bowel are absent.

Prognosis of CMUSE remains uncertain. Patients were previously referred for surgery because of symptomatic small intestinal strictures. However, the postoperative recurrence rate is high. Matsumoto (33) reports a single case of CMUSE followed up for 40 years since 1963. This patient was operated on seven times because of recurrence of tight stenoses and several resections of the small bowel had to be performed. Nowadays, endoscopic treatment of symptomatic stenoses should be tried first. Therapy with glucocorticosteroids is a treatment of choice. However, most patients develop corticosteroid dependence.

In conclusion, CMUSE, although a rare condition affecting the small bowel, should always be considered when chronic or relapsing moderate ileous episodes result from multiple small intestinal strictures and multiple shallow ulcers of the small bowel are found (in the absence of Crohn's disease, NSAID use or small intestinal infection). Double balloon enteroscopy enables precise diagnostic work, possible endoscopic treatment of stenoses, may obviate the need for surgery and prevent excessive small bowel resections.

The study was supported by research project $M Z O$ 00179906 from the Ministry of Health.

\section{References}

1. Birkedal-Hansen $\mathrm{H}$, Moore WG, Bodden MK, et al. Matrix metalloproteinases: a review. Crit Rev Oral Biol Med 1993;4:197-250.

2. Bokemeyer B, Schmidt FW, Galanski M. Cryptogenic multifocal stenosing enteritis (article in German). Z Gastroenterol 1987;25:745-8. 
3. Boydstun JS, Gaffey TA, Bartholomew LG. Clinicopathologic study of nonspecific ulcers of the small intestine. Dig Dis Sci 1981;26:911-16.

4. Cattan B, Frumusan P, Pineau P, Nivet P, Habib R. Stenosing ulcer of the ileum (article in French). Arch Mal Appar Dig Mal Nutr 1957;46:984-90

5. Capurso G, Lahner E, Pallotta N, et al. Iron deficiency anemia caused by nonspecific (idiopathic) small bowel ulceration: an uncommon presentation of an uncommon disease. Can J Gastroenterol 2002; 16:855-9.

6. Cavallaro V, Racalbuto A, Rusello D, Succi L, Fragati G, Catania V. Intestinal perforation caused by non specific idiopathic ulcer of the small intestine. A case report. Ital J Surg Sci 1989;19:395-8.

7. Chagnon JP, Devars du Mayne JF, Marche C, Vissuzaine C, Cerf M. Multifocal cryptogenic stenosing enteritis: an autonomous entity? (Article in French). Gastroenterol Clin Biol 1984;8:808-13.

8. Chamberlain RS, Atkins S, Saini N, White JC. Ileal perforation caused by cytomegalovirus infection in a critically ill adult. J Clin Gastroenterol 2000:30:432-35.

9. Chang DK, Kim JJ, Choi H, Eun CS, et al. Double balloon endoscopy in smal intestinal Crohn's disease and other inflammatory diseases such as cryptogenic multifocal ulcerous stenosing enteritis (CMUSE). Gastrointest Endosc 2007;66: 96-98.

10. Debray C, Besancon F, Harduoin JP, Martin E, Marche C, Khoury K. Cryptogenic plurifocal ulcerative stenosing enteritis (article in French). Arch Mal Appar Dig Mal Nutr 1964;53:193-206.

11. Deniz K, Ozseker HS, Balas S, Akpýnar E, Sökmensüer C. Intestinal involvement in Wegener's granulomatosis. J Gastroenterol Liver Dis 2007;16:329-31.

12. Doutre LP, Paccalin J, Périssat J, Traissac FJ. Plurifocal ulcerous stenosing enteritis (article in French). Arch Mal Appar Dig Mal Nutr 1966;55:537-40.

13. Ebert EC. Gastric and enteric involvement in progressive systemic sclerosis. J Clin Gastroenterol 2008;42:5-12.

14. Elizalde Apestegui IR, Arín Letamendía A, Zozaya Alvarez E, Jiménez Pérez FJ, Zozaya Urmeneta JM, Arellano Aburto J. Chronic non granulomatous ulcerative jejunitis (article in Spanish). Gastroenterol Hepatol 1998;21:342-5.

15. Ersoy O, Harmanci O, Aydinli M, Sivri B, Bayraktar Y. Capability of capsule en doscopy in detecting small bowel ulcers. Dig Dis Sci 2009;54:136-41.

16. Fraile G, Norman F, Requero ME, Defargues V, Redondo C. Cryptogenic multifocal ulcerous stenosing enteritis (CMUSE) in a man with a diagnosis of X-linked reticulate pigmentary disorder (PDR). Scand J Gastroenterol 2008;43:506-10.

17. Freeman HJ. Refractory celiac disease and sprue-like intestinal disease. World J Gastroenterol 2008;14:828-30.

18. Gaucher P, Bigard MA, Champigneulle B, Colin D. Cryptogenic multifocal stenosing enteritis: a new case. Gastroenterol Clin Biol 1985;9:453.

19. Hamza M, Eleuch M, Kchir N, Zitouma M. Ileal perforation in 3 cases of Behcet disease (article in French). Ann Med Interne (Paris) 1994;145:99-102.

20. Hayashi K, Horie Y, Takahata H, Adachi Y, Kitamura Y, Kato M. Ileal ulcers and cytomegalovirus in a case of Churg-Strauss syndrome. Arch Pathol Lab Med 2005; 129:e141-e143.

21. Hizawa K, Kai H, Hasegawa $\mathrm{H}$, et al. Ileal perforation in diffuse intestinal Behce disease: report of a case. Surg Today 2002;32:167-9.

22. Hopkins JE, Deaver JM. Stenosing small-bowel ulceration. Pennsylvania Med 1966;69:35-9.

23. Hussey S, Bourke B, Broderick A, Phelan E, McDermott M. Cryptogenic, multifocal, ulcerous, and stenosing enteritis as a manifestation of enterocolic venopathy. J Pediatr Gastroenterol Nutr 2008;47:107-9.

24. Isik B, Ara C, Kirimlioglu H, Sogutlu G, Yilmaz M, Yilmaz S, Kirimlioglu V. Single or multiple perforations with varying locations as a complication of intestinal Behcet disease: report of three cases. Scand J Gastroenterol 2005;40:599-603.

25. Jeffries GH, Steinberg H, Sleisenger MH. Chronic ulcerative (nongranulomatous) jejunitis. Am J Med 1968;44:47-59.

26. Kakegawa S, Kojima M, Ohwada S, et al. Idiopathic ulcer of the small bowel containing numerous plasma cells: case resembling mucosa-associated lymphoid tissue lymphoma. J Gastroenterol Hepatol 2005;20:1304-7.

27. Kaneki T, Kawashima A, Hayano T, et al. Churg-Strauss syndrome (allergic granulomatous angiitis) presenting with ileus caused by ischaemic ileal ulcer J Gastroenterol 1998;33:112-16.

28. Kiguchi H, Kasahara K, Mochizuki M, et al. Weber-Christian disease associated with multiple perfeorations of the ileum and colon. Am J Gastroenterol 1989;84:808-10

29. Kopáčová M, Rejchrt S, Tachecí I, Bureš J. Hyperamylasemia of uncertain significance associated with oral double-balloon enteroscopy. Gastrointest Endosc 2007;66:1133-8.

30. Kurata A, Nonaka T, Arimura Y, et al. Multiple ulcers with perforation of the small intestine in Buerger's disease: a case report. Gastroenterology 2003;125:911-16.

31. Li B, Shi YK, He XH, et al. Primary non-Hodgkin lymphomas in the small and large intestine: clinicopathological characteristics and management of 40 patients. Int J Hematol 2008;87:375-381.

32. Lindholmer B, Nyman E, Raef L. Nonspecific stenosing ulceration of the small bowel: a preliminary report. Acta Chir Scand 1964;128:310-11.

33. Matsumoto T, Iida M, Matsui T, Yao T. Chronic nonspecific multiple ulcers of the small intestine: a proposal of the entity from Japanese gastroenterologists to Western enteroscopists. Gastrointest Endosc 2007;66:99-107.

34. Matsumoto T, Iida M, Matsui T, et al. Non-specific multiple ulcers of the small intestine unrelated to non-steroidal anti-inflammatory drugs. J Clin Pathol 2004;57:1145-50

35. Matsumoto T, Nakamura S, Esaki M. Endoscopic features of chronic nonspecific multiple ulcers of the small intestine: comparison with non-steroidal anti-inflammatory drug-induced enteropathy. Dig Dis Sci 2006;51:1357-63.

36. Nakamura Y, Sakurai Y, Matsubara T, et al. Multiple perforated ulcers of the small intestine associated with allergic granulomatous angiitis: report of a case. Surg Today 2002;32:541-6.

37. Perlemuter G, Guillevin L, Legman P, Weiss L, Couturier D, Chaussade S. Cryptogenetic multifocal ulcerous stenosing enteritis: an atypical type of vasculitis or a disease mimicking vasculitis. Gut 2001;48:333-8

38. Perlemuter G, Chaussade S, Soubrane O, et al. Multifocal stenosing ulcerations of the small intestine revealing vasculitis associated with $\mathrm{C} 2$ deficiency. Gastroenterology 1996:110:1628-32.

39. Rejchrt S, Kopáčová M, Tachecí I, Bureš J. Interventional double balloon endoscopy for Crohn's, gastrointestinal bleeding, and foreign body extraction. Tech Gastrointest Endosc 2008;10:101-6.

40. Remacha Tomey B, Velicia Llames B, del Villar A, Fernandéz Orcajo P, CaroPatón Gomez A. Eosinophilic enteritis causing intestinal obstruction (article in Spanish). Gastroenterol Hepatol 1999;22:352-55

41. Rocha A, Artigas V. Stenosing ulcerous disease of the jejuno-ileum (article in French). Arch Mal Appar Dig Mal Nutr 1959;48:1230-6.

42. Santolaria S, Cabezali R, Ortego J, Castiella T, Salinas JC, Lanas A. Diaphragm disease of the small bowel: a case without apparent nonsteroidal antiinflammatory drug use. J Clin Gastroenterol 2001;32:344-6.

43. Sasamura H, Nakamoto H, Ryuzaki M, et al. Repeated intestinal ulcerations in a patient with systemic lupus erythematosus and high serum antiphospholipid antibody level. South Med J 1991;84:515-17.

44. Spencer H, Kitsanta P, Riley S. Cryptogenous multifocal ulcerous stenosing enteritis. J Roy Soc Med 2004;97:538-40.

45. Tachecí I, Ryška A, Rejchrt S, Kopáčová M, Hořava V, Bureš J. Spontaneous disintegration of a retained video capsule in a patient with cryptogenic multifocal ulcerous stenosing enteritis: a rare complication. Endoscopy 2008;40, S02: E104-E105

46. Thomas WEG, Williamson RCN. Nonspecific small bowel ulceration. Postgrad Med J 1985;61:587-91.

47. Vozenin-Brotons MC, Milliat F, Sabourin JC, et al. Fibrogenic signals in patient with radiation enteritis are associated with increased connective tissue growth factor expression. Int J Radiat Oncol Biol Phys 2003;56:561-72.

48. Wig JD, Monga NK, Kaushik SP, Sachdeva HS. Non-specific stenotic lesions of small bowel. J Indian Med Assoc 1975;64:1-3.

49. Xing Z, Jordana M, Braciak K, Ohtoshi T, Gauldie J. Lipopolysaccharide induces expression of granulocyte/macrophage colony-stimulating factor, interleukin-8, and interleukin- 6 in human nasal, but not lung, fibroblasts: evidence for heterogeneity within the respiratory tract. Am J Respir Cell Mol Biol 1993;9:255-63.

50. Yoshida N, Wakabayashi N, Nomura K, et al. Ileal mucosa-associated lymphoid tissue lymphoma showing several ulcer scars detected using double-baloon endoscopy. Endoscopy 2004;36:1022-4.

Received: $27 / 01 / 2010$.

Accepted: 05/03/2010.

\section{Corresponding author:}

Darina Kohoutová, MD, $2^{\text {nd }}$ Department of Internal Medicine, University Hospital, Sokolská 581, 50005 Hradec Králové, Czech Republic; e-mail: darina.kohoutova@seznam.cz 